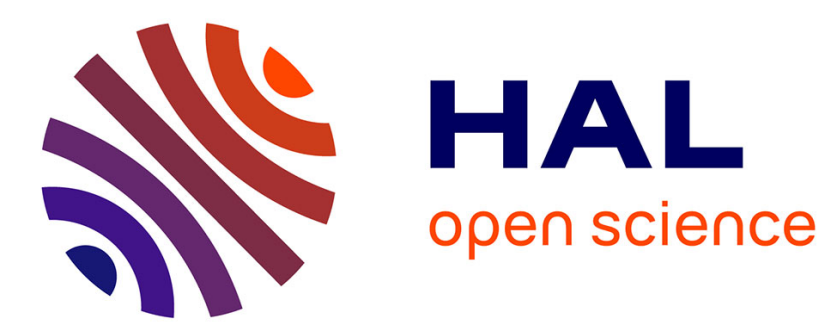

\title{
Multilayer Hierarchical Nanofibrillar Electrodes with Tunable Lacunarity with 2D like Pt Deposits for PEMFC
}

Giorgio Ercolano, Filippo Farina, Sara Cavaliere, Deborah J Jones, Jacques J

Rozière

\section{To cite this version:}

Giorgio Ercolano, Filippo Farina, Sara Cavaliere, Deborah J Jones, Jacques J Rozière. Multilayer Hierarchical Nanofibrillar Electrodes with Tunable Lacunarity with 2D like Pt Deposits for PEMFC. ECS Transactions, 2017, 80 (8), pp.757-762. 10.1149/08008.0757ecst . hal-01615244

\author{
HAL Id: hal-01615244 \\ https://hal.science/hal-01615244
}

Submitted on 5 Jun 2018

HAL is a multi-disciplinary open access archive for the deposit and dissemination of scientific research documents, whether they are published or not. The documents may come from teaching and research institutions in France or abroad, or from public or private research centers.
L'archive ouverte pluridisciplinaire HAL, est destinée au dépôt et à la diffusion de documents scientifiques de niveau recherche, publiés ou non, émanant des établissements d'enseignement et de recherche français ou étrangers, des laboratoires publics ou privés. 


\title{
Multilayer Hierarchical Nanofibrillar Electrodes with Tunable Lacunarity with 2D like Pt Deposits for PEMFC
}

\author{
G. Ercolano ${ }^{\text {a }}$, F.Farina ${ }^{\text {a }}$, S. Cavaliere, D. J.Jones ${ }^{\text {a }}$, and J. Rozière ${ }^{a}$ \\ ${ }^{a}$ Institut Charles Gerhardt, UMR CNRS 5253, Agrégats Interfaces et Matériaux pour \\ l'Energie, Université de Montpellier, 34095 Montpellier Cedex 5, France
}

\begin{abstract}
Here we present a novel approach to electrocatalyst layer design for PEMFC. Pt is conformally electrodeposited around the surface of carbon nanotubes grown on a self-standing nanofibrous electrode (NFE). We found that by combining two cost-effective and up-scalable techniques, electrospinning and electrodeposition it is possible to produce a layered electrode with tunable lacunarity and engineer the surface area distribution along the electrode thickness and in turn the Pt content distribution. It is possible to obtain an electrocatalyst with outstanding Pt exploitation and high durability while minimizing fabrication complexity. We produced hierarchical 3D electrocatalyst layers with tunable morphology that can be used directly in a membrane electrode assembly, allowing the complete exploitation of their highly porous structure, in a similar fashion to other 3D macroscopic assembly techniques.
\end{abstract}

\section{Introduction}

We developed a novel class of electrocatalysts intermediate between carbon black decorated with platinum nanoparticles and existing extended film catalysts that comprised platinum conformally electrodeposited around the carbon nanofibres of a selfstanding electrode. We found that combining two cost-effective and up-scalable techniques, electrospinning and high over potential electrodeposition, it is possible to obtain an electrocatalyst with outstanding platinum exploitation and high durability while minimizing fabrication complexity. We produced electrocatalyst layers with tunable morphology that could be characterized directly and potentially used as such, removing the need to prepare inks in a similar fashion to conventional NSTF (1) (nanostructured thin films) or other 3D macroscopic assembly techniques (2-4). These structured 3D electrocatalyst layers have high electrical conductivity for fast charge transport, and hierarchical pores for efficient reactant mass transportation (5). The carbon nanofibrous electrodes we used comprised polyacrylonitrile (PAN) derived electrospun carbon nanofibers, that we have demonstrated to be a potentially viable alternative carbon support for electrocatalysts (6-10).

In particular, we showed how controlling the pulse length in pulsed electrodeposition can be used to control coverage density and diameter of platinum clusters. The ECSAs we measured for these novel electrocatalysts were up to $120 \mathrm{~m}^{2} \mathrm{~g}^{-1}$, which is higher than most highly optimized commercial catalysts currently available and the stability was up to 3 times higher than that achieved with conventional $\mathrm{Pt} / \mathrm{C}$, and without the introduction of more stable / less conductive metal oxide supports (11). 
However, integration of the self-standing electrodes in an MEA showed that these catalyst layers, while showing high stability and high platinum specific surface areas, were also characterized by low density, low support surface area and anisotropic connectivity. Ultimately, the combination of aall of these factors translated into MEAsin which proton transport from the deeper layers of the electrodes to the membrane surfaces was difficult, and having low maximum platinum loading $\left(<0.05 \mathrm{mg} \mathrm{cm} \mathrm{cm}^{-2}\right)$. We developed two approaches to self-standing electrodes of increased density: nanofiber alignment and carbon nanotube growth from carbon nanofibers. Here we demonstrate that it is possible to modify the layer morphology with consequent increase of the density, connectivity and surface area of the electrospun carbon nanofiber support.

\section{Experimental Details}

Nanofiber Web Preparation

Polyacrylonitrile (PAN, Mw=150,000, Sigma Aldrich) based carbon fibers were prepared by electrospinning followed by thermal treatments as already reported (1214). In detail, $8 \%_{\mathrm{wt}}$ to $12 \%_{\mathrm{wt}}$ PAN solution in N,N-dimethylformamide (DMF,98\%, Sigma Aldrich) was fed to a metal needle via a syringe pump with a flow rate of 1 to $2 \mathrm{ml} / \mathrm{h}$. Under standard conditions, the drum collector was rotated at $300 \mathrm{RPM}$. Aligned nanofibers were obtained by increasing the rotation speed to 1500 RPM.

For the preparation of carbon nanotubes (CNT) on carbon nanofibers (CNF), metal precursors $(0.1 \mathrm{M}$ metal nitrates for $\mathrm{Al}, \mathrm{Cu}, \mathrm{Ni}, \mathrm{Ag}$, acetylacetonate for $\mathrm{Fe}$, chloroplatinic acid hexahydrate for $\mathrm{Pt}$ and, acetate for $\mathrm{Pd}$ ) were also added to the electrospinning solution. In all cases, an electric field of $15 \mathrm{kV}$ was applied between the needle and a metallic rotating drum collector placed $10 \mathrm{~cm}$ away. Asprepared nanofibers were collected in the form of non-woven webs. Fiber carbonization was realized by a two-step thermal treatment. First, oxidative stabilization was performed at $280{ }^{\circ} \mathrm{C}$ for $1 \mathrm{~h}$ followed by carbonization for $1 \mathrm{~h}$ under $\mathrm{N}_{2}$ at $1500{ }^{\circ} \mathrm{C}$ using a heating ramp of $1{ }^{\circ} \mathrm{C} / \mathrm{min}$ for the pure PAN and followed by a carbonization CNT growth step for the PAN + metal nanofibers. The produced carbon electrodes were subsequently treated at $80{ }^{\circ} \mathrm{C}$ in a $3 \mathrm{M} \mathrm{HNQ}$ solution for $5 \mathrm{hr}$.

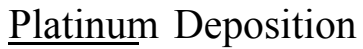

Pt electrodeposition was performed in a 2-electrode setup, where the counter electrode consisted of a $50 \times 50 \times 0.8 \mathrm{~mm}$ graphite foil facing the working electrode and kept $10 \mathrm{~mm}$ away; the latter was a $50 \times 50 \times 0.02$ to $0.05 \mathrm{~mm}$ carbon nanofibre selfstanding web. Both electrodes were immersed in a $\mathrm{N}_{2}$ saturated $0.1 \mathrm{M} \mathrm{H}_{2} \mathrm{PtCl}_{6} 5 \mathrm{H}_{2} \mathrm{O}$ solution and contacted using an electrodeposition cell designed in-house. The deposition voltage was cycled between $-3.0 \mathrm{~V}$ and $0.0 \mathrm{~V}$ for the desired number of pulses and duration. Samples were thoroughly washed with deionized water (18 M $\Omega$ $\mathrm{cm})$, dried and weighed on a microbalance. 


\section{Electrode Characterization}

The morphology of the electrospun materials, carbon nanotubes and the deposited platinum was analyzed by field emission-scanning electron microscopy (FE-SEM) using a Hitachi S-4800 microscope and by transmission electron microscopy (TEM) using a JEOL 2200FS (Source: FEG) microscope operating at $200 \mathrm{kV}$ equipped with a CCD camera Gatan USC (16 MP). For TEM analyses, samples were suspended in ethanol and sonicated before deposition onto carbon-coated copper grids while for cross sectional analysis a microtome was used on resin-encapsulated piece of web and slices were deposited on carbon-coated copper grids.

\section{Results and Discussion}

\section{$\underline{\text { Aligned carbon nanofiber electrodes }}$}

We first investigated the production of aligned carbon nanofiber electrodes for the densification of the support.

$\mathrm{a}$

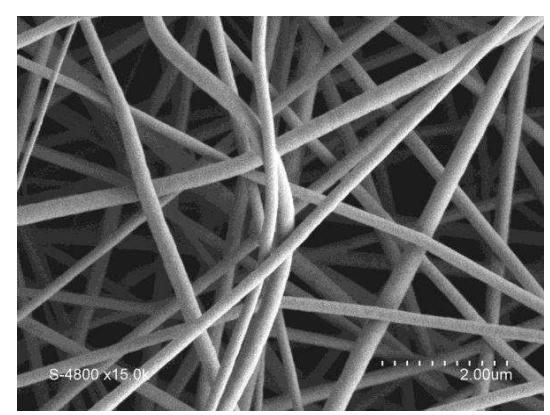

c

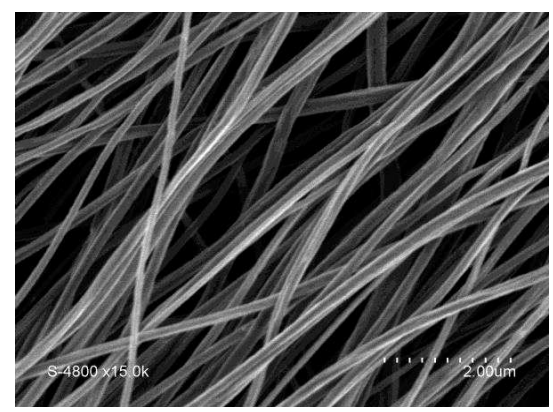

b

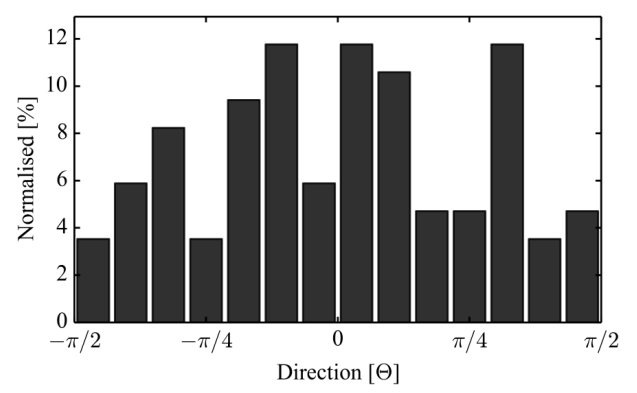

d

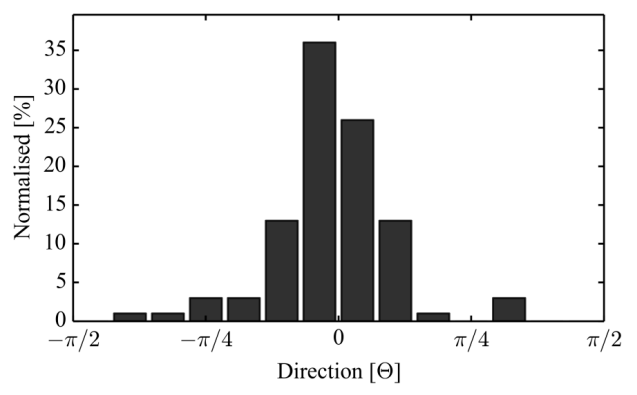

Figure 1. SEM images of non-aligned ${ }^{\mathrm{a}}$ and aligned $^{\mathrm{b}}$ electrospun carbon nanofiber webs and the respective alignment analysis ${ }^{\mathrm{c} \text { and } \mathrm{d}}$.

The aligned carbon nanofiber electrodes were obtained by increasing the rotation speed of the drum collector from the usual 300 RPM to 1500 RPM. The increased rotation speed of the drum generates a draw effect on the fibers, aligning them along the surface velocity vector. Figure 1 displays fibers obtained at 300 and 1500 RPM. A consequence of the alignment is an increase in the density of the electrode by around $30 \%$, unfortunately this densification comes with the introduction of even more anisotropy i.e. the fibers are not only aligned in planes parallels to the electrode surface, they are also aligned along a specific direction in these planes. 
$\underline{\text { Self-standing carbon nanofiber-carbon nanotube electrodes }}$

Another possible route to densify the electrodes and reduce the anisotropy of the connectivity is to grow carbon nanotubes (CNT) from the surface of the carbon nanofibers by doping the latter with CNT growth catalysts and performing a CVD growth during or after carbonization of the PAN (15). In our first study we used hexane vapor as a source of carbon for the formation of carbon nanotubes and iron acetylacetonate as iron nanoparticle precursor in the electrospinning solution.(figure 2a-b). Using this technique, we were able to obtain carbon nanotube-carbon nanofibre (CNF-CNT) electrodes and also control the length of the carbon nanotubes by changing the exposure times to the hexane vapor. A problem we had to resolve for successful and reliable use of this approach for substrate fabrication was the low yield and highly variable carbon nanotube growth.

a

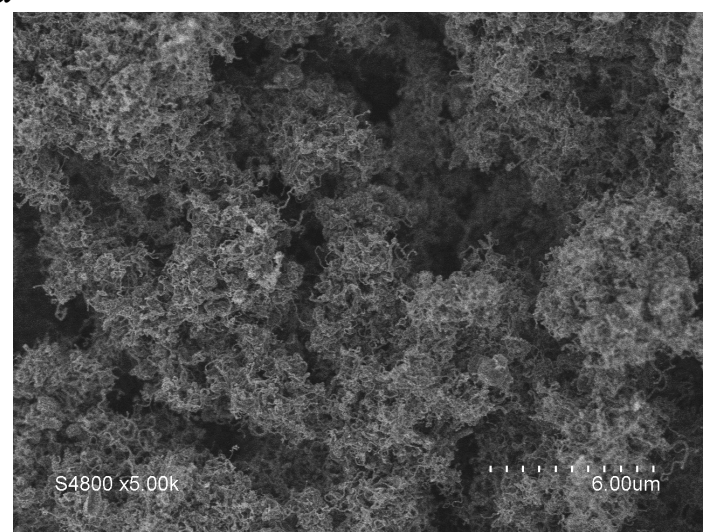

$\mathrm{b}$

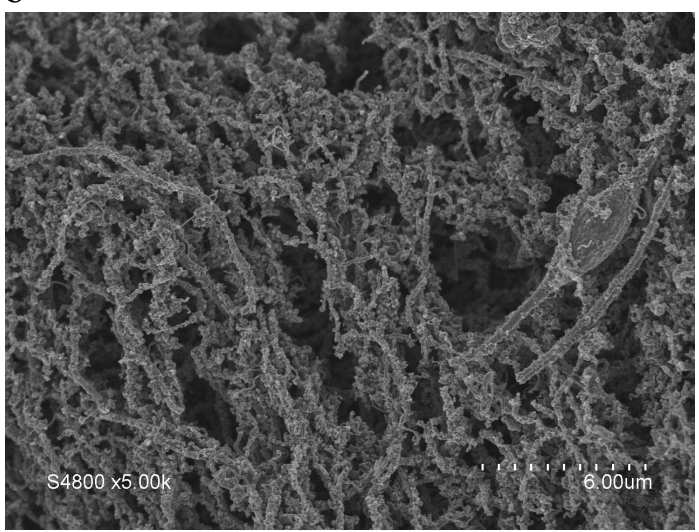

Figure 2. SEM images of long ${ }^{\mathrm{a}}$ and short ${ }^{\mathrm{b}}$ carbon nanotube growth directly from the surface of iron doped electrospun carbon nanofibers.

To increase the yield of the carbon nanotubes, we decided to completely revamp the thermal process as well as the carbon nanotube growth catalyst; in particular we investigated the growth of carbon nanotubes at $900{ }^{\circ} \mathrm{C}$ using ethanol vapor as the carbon source and palladium, platinum, silver, copper, aluminum, iron and, nickel catalysts. The only two precursors that yielded nanotubes were nickel and iron. Interestingly iron resulted in straight nanotubes while nickel gave curly ones (figure 3).
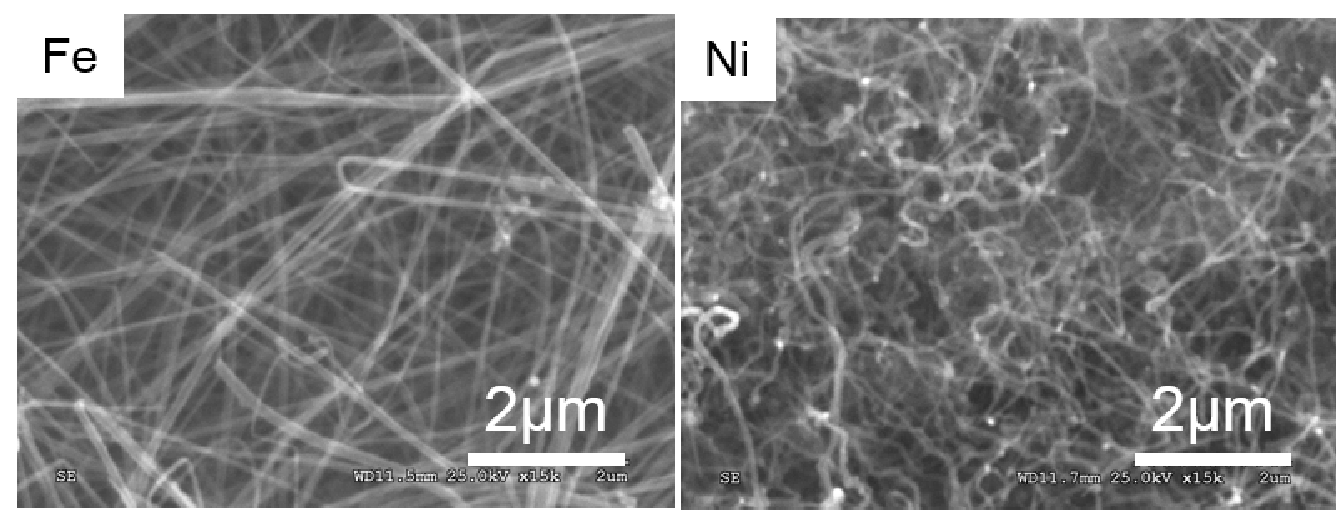

Figure 3. SEM images of carbon nanotubes obtained using either iron or nickel as growth catalysts. 
The metal nanoparticles that are necessary for the nanotube growth have to be removed before the electrodes are considered viable for MEA operation as iron and nickel dissolution is a major concern with regard to reduced membrane/ ionomer conductivity and membrane degradation. .However, acid based leaching is capable of completely removing accessible iron. The cyclic voltammetry shown in figure $4 \mathrm{a}$ demonstrates that there is no residual accessible iron after the leaching process, furthermore additional evidence was also obtained by TEM investigation that only showed the presence of embedded iron after the leaching. The embedded iron is completely enclosed in the nanotubes and a layer of carbide is also present on the surface of these iron particles, and therefore there should not be concern for further iron dissolution occurring during MEA operation.

a

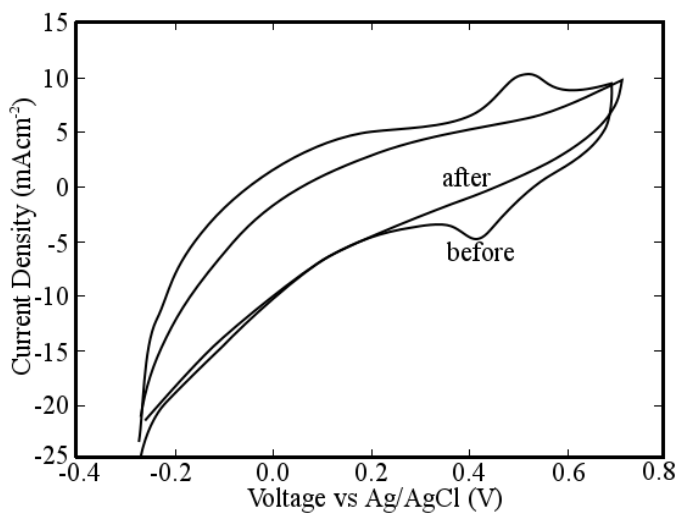

b

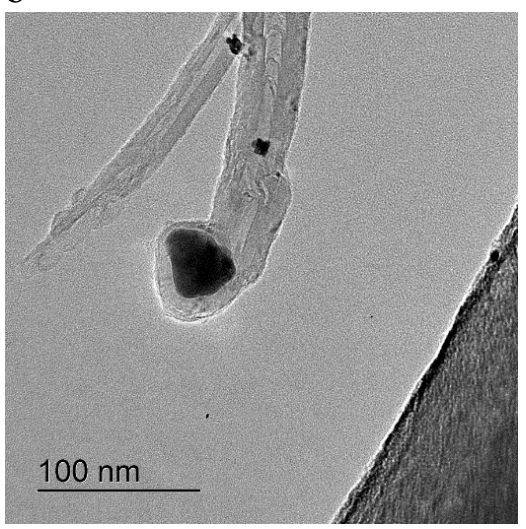

Figure 4. Cyclic voltammetry in $0.1 \mathrm{M} \mathrm{HClO}_{4}$ of a CNF-CNT electrode before and after iron leaching ${ }^{\mathrm{a}}$ and, TEM images of an iron nanoparticle embedded in a multi-wall carbon nanotube ${ }^{\mathrm{b}}$.

With a reliable and reproducible process defined for the production of multi-layered hierarchical self-standing CNF-CNT electrodes with tuneable lacunarity, we were able to begin platinisation by high overpotential electrodeposition (11) (an example of a platinised electrode is given in figure 5).

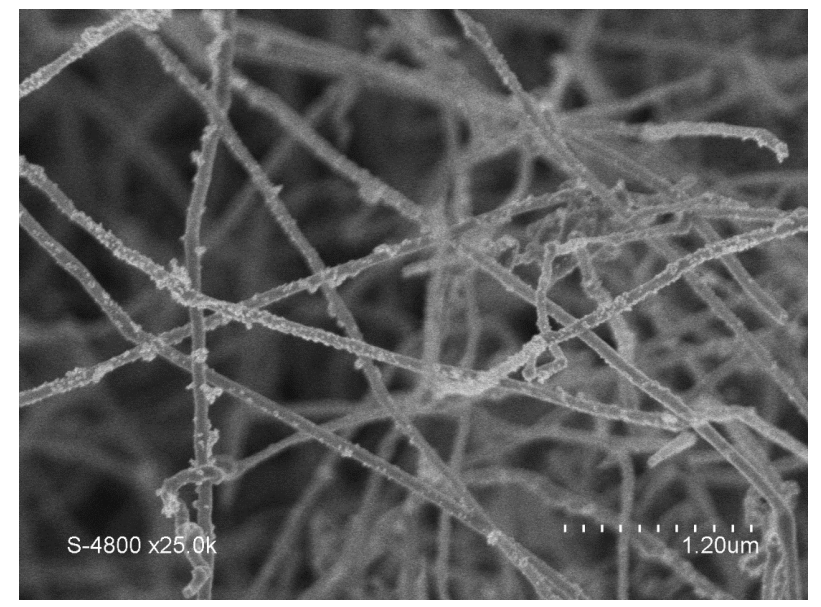

Figure 5. SEM image of the surface of a platinised CNF-CNT electrode. 


\section{Conclusion}

We have developed a new process to modify the morphology for the selfstanding electrodes in a way that could remove the drawbacks observed during the earlier implementation of electrospun carbon nanofiber self-standing electrodes in MEAs. This new process allows control and tuning of the lacunarity of the electrodes. Furthermore, the presence of nanotubes not aligned to planes parallel to the electrodes should reduce the anisotropicity of the connectivity thence promoting more efficient proton transport to the membrane.

\section{Acknowledgments}

This project has received funding from the Fuel Cells and Hydrogen 2 Joint Undertaking under grant agreement No 700127 INSPIRE. This Joint Undertaking receives support from the European Union's Horizon 2020 research and innovation programme.

\section{References}

1. M. K. Debe, A. K. Schmoeckel, G. D. Vernstrom and R. Atanasoski, J. Power Sources, 161, 1002, (2006).

2. S. Chen, J. Duan, M. Jaroniec and S. Z. Qiao, Angew. Chem. Int. Ed. Engl., 52, 13567, (2013).

3. S. Chen, J. Duan, M. Jaroniec and S.-Z. Qiao, Adv. Mater., 26, 2925, (2014).

4. H.-J. Qiu, Y. Ito, W. Cong, Y. Tan, P. Liu, A. Hirata, T. Fujita, Z. Tang and M. Chen, Angew. Chem. Int. Ed. Engl., 54, 14031, (2015).

5. Y. Zheng, Y. Jiao and S. Z. Qiao, Adv. Mater., 27, 5372, (2015).

6. D. Sebastián, A. G. Ruíz, I. Suelves, R. Moliner, M. J. Lázaro, V. Baglio, A. Stassi and A. S. Aricò, Appl. Catal. B Environ., 115-116, 269, (2012).

7. B. Wu, D. Hu, Y. Kuang, Y. Yu, X. Zhang and J. Chen, Chem. Commun. (Camb)., 47, 5253, (2011).

8. J.-H. Park, Y.-W. Ju, S.-H. Park, H.-R. Jung, K.-S. Yang and W.-J. Lee, J. Appl. Electrochem., 39, 1229, (2009).

9. Z. Lin, L. Ji and X. Zhang, Electrochim. Acta, 54, 7042, (2009).

10. M. Li, Y. Chang, G. Han and B. Yang, J. Power Sources, 196, 7973, (2011).

11. G. Ercolano, F. Farina, S. Cavaliere, D. J. Jones and J. Rozière, J. Mater. Chem. A, 5, 3974, (2017).

12. C.-K. Liu, K. Lai, W. Liu, M. Yao and R.-J. Sun, Polym. Int., 58, 1341, (2009).

13. N. Yusof and A. F. Ismail, J. Anal. Appl. Pyrolysis, 93, 1, (2012).

14. I. Savych, J. Bernard d'Arbigny, S. Subianto, S. Cavaliere, D. J. Jones and J. Rozière, J. Power Sources, 257, 147, (2014).

15. H. Hou and D. H. Reneker, Adv. Mater., 16, 69, (2004). 